\title{
Epidemiological Pattern of Bullying Among School Children in Mazandaran Province, Iran
}

\author{
Meysam Rezapour ${ }^{1}$; Hamid Soori ${ }^{2, *}$; Soheyla Khodakarim ${ }^{3}$ \\ ${ }_{1}^{1}$ School of Public Health, Shahid Beheshti University of Medical Sciences, Tehran, IR Iran \\ ${ }^{2}$ Safety Promotion and Injury Prevention Research Center, School of Public Health, Shahid Beheshti University of Medical Sciences, Tehran, IR Iran \\ ${ }^{3}$ Department of Epidemiology, School of Public Health, Shahid Beheshti University of Medical Sciences, Tehran, IR Iran \\ ${ }^{*}$ Corresponding author: Hamid Soori, Safety Promotion and Injury Prevention Research Center, School of Public Health, Shahid Beheshti Unive \\ Iran. Tel: +98-22439980, E-mail: hsoori@yahoo.com \\ Received: August 5, 2014; Revised: September 2, 2014; Accepted: October 19, 2014 \\ Background:School bullying, the most common type of school violence, comprises a spectrum oggressive behaviors thatinvolve both
perpetrators and victims.
Objectives: The current study aimed to investigate the extent and nature of school bullying among middle school students in the North
} of Iran.

Patients and Methods: A cross-sectional study was conducted on a sample of 834 Iranian middle school students. Participants completed a self-report anonymous questionnaire measuring bullying and victimization (Iranian-Olweus bullying questionnaire). Descriptive statistics and the Pearson's chi-squared test and multinomial logistic regressions with area, gender and grade variables were applied. Results: Prevalence rates of bullying behaviors based on the cut-off point at 2 or 3 times a month were $5.4 \%$ for only bully, 22.1\% for only victim and $11 \%$ for both bully-victim. The prevalence of each form of victimization were $24.7 \%$ verbal, $15 \%$ relational, $10.3 \%$ physical and for each form of bullies 11\% verbal, $5.3 \%$ relational, $6.4 \%$ physical. Boys were more involved in all forms of bullying behaviors. The students from rural areas were more involved in bullying. The most common places of victimization were the playground or athletic fields. The majority of victims were bullied by their classmates.

Conclusions: Different forms of bullying have a distinct nature and the epidemiological pattern indicates that bullying exists in the Iranian schools. Thus, the effective bullying prevention and app ropriate intervention programs are recommended.

Keywords:Crime Victim; bullying; Epidemiology; Adolescent

\section{Background}

School bullying, the widespread ype of school includes a spectrum of aggressive beha both bullies and victims (1) Bullying is defined as a special form of aggression, which is intentional, repeated (2), and involves an imbalance of power between the victim and bullies (3). Three forms of bullying are identified as; only bullies (those who bully other adolescents only); only victims (adolescents who are victimized by bullies); bully-victims (adolescents who are inyolved in bullying other adolescents and are also victims of bullying) (4). Bullying has many forms such as physical (e.g. hitting, pushing, and kicking), verbal (e.g. name-calling and teasing, aggressively), relational or social (e.g. social exclusion and spreading rumors), and other ways (cyber-bullying, etc. , among which physical and verbal bullying are both considered as direct types, and relational bullying indirect type of bullying $(5,6)$.

In different studies conducted by diverse instruments, a notable variability in the prevalence of bullying was reported. For example, in a nationally representative sample of adolescents in the United States, Nansel et al.

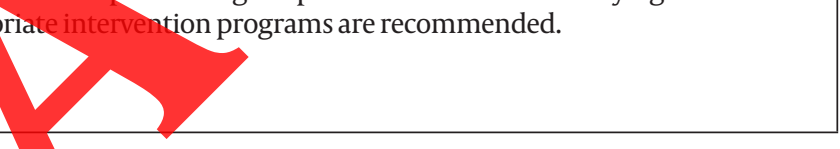
(3) showed that the prevalence of frequent involvement in school bullying is $29.9 \%$, $(13.0 \%$ as bullies, $10.6 \%$ as victims, and $6.3 \%$ as both). Another study in Cyprus revealed that $17 \%$ of the children are involved in bullying and victimization (7). In a Korean study, $40 \%$ of the children were involved in school bullying (17.0\% as bullies, $14.0 \%$ as victims, and $9.0 \%$ as both) (1). Verbal bullying was found more common in many studies $(5,8,9)$. Results of a study in Turkey showed that $33.5,35.5 \%$, and $28.3 \%$ of the students had been bullied, at least once during the academic year, verbally, physically, and relationally, respectively (9). Studies show that bullying is more common in boys than girls $(3,4,10,11)$ and they are more likely to be involved in direct bullying $(5,12)$. However, exposure to bullying varies across different countries, ranging from 8.6\% to $45.2 \%$ among boys, and $4.8 \%$ to $35.8 \%$ among girls (13). Bullying takes place in different locations; the playgrounds, athletic fields, and the classrooms (while the teachers are absent) were the most common places, according to many studies $(14,15)$. Most researchers believed that bullying has extensive negative consequences

Copyright (C) 2014, Kashan University of Medical Sciences. This is an open-access article distributed under the terms of the Creative Commons Attribution-NonCommercial 4.0 International License (http://creativecommons.org/licenses/by-nc/4.0/) which permits copy and redistribute the material just in noncommercial usages, provided the original work is properly cited. 
for the victims, bullies, or both (16); for example, they are associated with alcohol misuse (17), substance misuse (18), school achievements and psychological well-being for both victims and perpetrators (5).

Some studies have found that children involved in bullying are at increased risk for psychosomatic problems such as headache, backache, abdominal pain and also sleeping problems, bad appetite, and bed-wetting (19). Research on the prevalence and location of bullying is conducted in many high income countries, including Norway, Sweden, Denmark, Finland, Germany, Spain, Italy, England, Scotland, Ireland, Australia, Canada, and the United States (20), and also in Asian countries including Japan and Korea. However, in the Eastern Mediterranean states the epidemiology of bullying among schoolchildren is not reported well.

\section{Objectives}

The current study aimed to investigate the extent and nature of school bullying as an epidemiological approach among the middle school students in North of Iran.

\section{Patients and Methods}

The participants were 834 pupils from the 8 th and 9th grades of 26 middle schools randomly selected from public schools in the urban and rural areas of Maza province in North of Iran. Sampling procedure was stratified-clustering, according to the students' population at strata (area, gender) and each of the schools as cluster randomly selected with an equal number of studen from the 8 th and 9 th grades.

Permission to carry out the the educational authority formed consent letters were obtained from the Community Parents and Educators of the selected schools. Data were collected through anonymous self-report questionnaires distributed in the classrooms and completed under the supervision of trained co-researchers. The selected pupils were informed about the purposes and importance of the study, and they were assured about the confidentiality of their answers. They were also told that it was not obligatory to complete the questionnaire. No time limit was imposed; bowever, the average time to ires was about half an hour. tion, the Iranian yalidated version (21) of Olweus bullying OBQ) $(5,11,22-26)$ was employed, which as reported reliable and valid. The obtained reliability and validity for 9 items of perpetrator bullying with Cronbach's Alpha was 0.81, and the exploratory factor analysis (EFA) with Varimax rotation revealed 4 factors solution explaining $73 \%$ of the total variance (forms of perpetrator bullying): verbal (3 items), relational ( 2 items), physical ( 2 items), and other forms ( 2 items), also the obtained reliability and validity for 10 items of victimization bullying with Cronbach's alpha was 0.80 , and the EFA with Vari- max rotation revealed 4 factors solution explaining 64\% of the total variance. Confirmatory factor analysis (CFA) confirmed the four-factor structure both victimization and perpetration of bullying scales. For the purpose of the present study, only the questions measuring frequency of bullying and victimization types were analyzed. Students were asked to indicate how often they bullied others or were victimized in the last three months.

The cutoff point of 2 or 3 times a month recommend as the most suitable criteria for break up involved anc noninvolved in bullying (11) was addressed.

All analyses were conducted using SPSS fo version 16.0. To analyze each orm of bullying the tics and multinomial logistic regressions were used.Descriptive analyses were conducted to measure the prevalence of bullying and victimization, and also overall and simple statistical procedures based on the chi-squared tests. Multinomial logistic regression models were used to compare bullies, victims, and bully-victims with those never involved, considering the background variables (area, gender and grade).

\section{Results}

participants were 417 grade 8 and 417 grade 9 middle school pupils. Overall, 412 (49.4. \%) were girls, and 553 (66.3\%) from the uban areas. The mean age of the pupils was 15 years. Table 1 presents the prevalence rate of involvement in different forms of bullying among middle school children a couple of months prior to data collection. Overall 38.5\% of pupils were victims of different forms of bullying. Bullying was more common among yictims $(22.1 \%)$ and $82.1 \%$ of them was verbal form. Table 2 shows the rate of involvement in each form of victimization and bullies by gender, area and grade. As a victim, verbal and physical bullying was more common among boys $(\mathrm{P}<0.001)$ with no significant differences by residential area and school grade. As bullies, there were significant differences for verbal and other forms of bullying by gender and residential area. There was also a statistically significant difference for relational and physical forms of bullying by sex among bullies.

Table 3 shows the occurrence locations of bullying among the subjects. Overall, playgrounds and sport fields (24.0\%), on the way to and from the school (13.9\%) and in the classroom when the teachers not available were the most common places for bullying. Regarding gender, there was a significant difference among some places of bullying such as playground or sport field and on the way to and from school.

Multinomial logistic regressions were performed for each of the four forms of bullying as physical, verbal, relational, others, and total. In each of the four multinomial logistic regressions, the bullying classification was the outcome variable, with noninvolved as the reference category, and with area, gender and grade variables as predictors. The odds ratios and their corresponding 95\% confidence intervals from the multivariate analyses are 
reported in Table 4.

In total, pupils from rural areas were more likely to be involved in bullying for both bullies and victims in form of verbal. Boys compared to girls were more likely to be involved in bullying, totally and in different categories (bullies, victims, and bully-victims) for physical bullying. They were also more likely to be involved in verbal bullying. There was no difference between the 8 th and 9th graders regarding the involvement in different forms and categories of bullying.

Table 1. Prevalence Rate of Involvement in Different Forms of Bullying Among Middle School Students $(\mathrm{n}=834)^{\mathrm{a}}$

\begin{tabular}{lcccc}
\hline \multicolumn{1}{c}{ Non Bullying } & Bully Only & Victim Only & Victim and Bully \\
\hline Verbal & $70.8(590)$ & $4.4(37)$ & $18.1(151)$ \\
Relational & $81.8(682)$ & $3.1(26)$ & $13.0(107)$ \\
Physical & $86.0(714)$ & $3.7(31)$ & $7.6(64)$ & $3.4(28)$ \\
Others & $93.4(776)$ & $2.2(19)$ & $22.1(184)$ & $2.2(18)$ \\
Total & $61.5(513)$ & $5.4(45)$ & & $11.0(92)$ \\
\hline a All of the values are present as No. (\%). & & &
\end{tabular}

Table 2. Rate of Involvement in Each Form of Victimization and Bullies by Gender, Area and Grade $(\mathrm{n}=834)^{\mathrm{a}, \mathrm{b}}$

\begin{tabular}{|c|c|c|c|c|c|c|c|c|c|}
\hline & \multirow[b]{2}{*}{ Total } & \multicolumn{3}{|c|}{ Gender } & \multicolumn{2}{|c|}{ ResidentialAtrea } & \multicolumn{3}{|c|}{ Grade of Schooling } \\
\hline & & Female & Male & P Value & Urban & urai PValue & 8th Grade & 9th Grade & PValue \\
\hline Verbal & $24.7(206)$ & $14.6(60)$ & $34.6(146)$ & $<0.001$ & $23.0(127)$ & NS & $26.1(109)$ & $23.3(97)$ & NS \\
\hline Relational & $15.0(125)$ & $14.1(58)$ & $15.9(67)$ & NS & $14.1(78)$ & NS & $15.3(64)$ & $14.7(61)$ & NS \\
\hline Physical & $10.3(86)$ & $6.3(26)$ & $14.2(60)$ & $<0.001$ & $9.6(53)$ & IVJ & $9.6(40)$ & $11.0(46)$ & NS \\
\hline Others & $4.4(37)$ & $3.2(13)$ & $5.7(24)$ & NS & & & $4.6(19)$ & $4.3(18)$ & NS \\
\hline Verbal & $11.0(92)$ & $7.3(30)$ & $14.7(62)$ & 0.001 & & 005 & $11.0(46)$ & $11.1(46)$ & NS \\
\hline Relational & $5.3(44)$ & $3.6(15)$ & $6.9(29)$ & 0 & & NS & $5.5(23)$ & $5.0(21)$ & NS \\
\hline Physical & $6.4(53)$ & $3.2(13)$ & & & & (19) & $7.2(30)$ & $5.5(23)$ & NS \\
\hline Others & $4.6(38)$ & $2.9(12)$ & & 0.006 & $3.4(19)$ & $6.8(19)$ & $4.8(20)$ & $4.3(18)$ & NS \\
\hline
\end{tabular}

a Abbreviation: NS, not significant.

$\mathrm{b}$ all of the values are presented as No.

Table 3. Locations of Bullying Among the Subjects

Place of bullying Total, $\% \quad$ Gender $\quad$ Grade of Schooling area

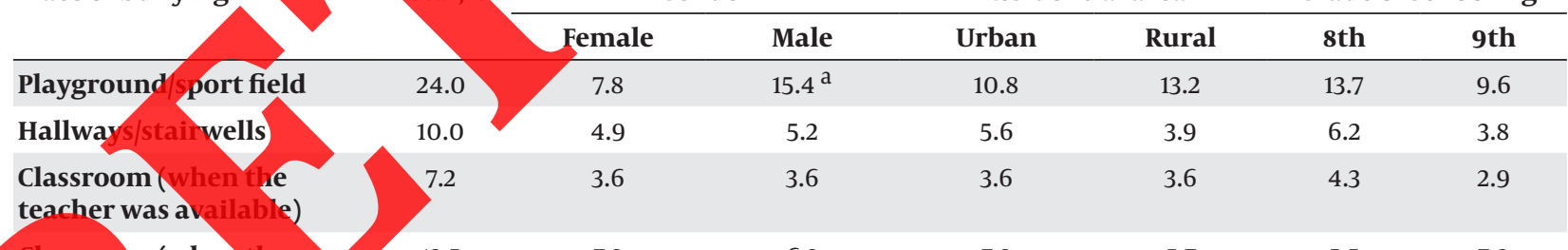

$\begin{array}{llllll}\text { Classroom (when the } & 7.3 & 6.2 & 7.2 & 5.7 & 7.5\end{array}$

teacher was not avai

Locker rooms 2.4

Lunch room

2.4
1.5
13.9

On the way to and from

school

In the sehool bus

Pray room

other Places

a P value $<0.01$.

\begin{tabular}{cccccc}
1.2 & 1.2 & 1.4 & 0.7 & 1.2 & 1.2 \\
0.7 & 0.7 & 0.7 & 0.7 & 1 & 0.5 \\
4.9 & $9.0^{\mathrm{a}}$ & 7.8 & 5.3 & 7.4 & 6.5 \\
2.2 & 0.7 & 1.6 & 1.1 & 1.9 & 1 \\
1.2 & 1.7 & 1.3 & 1.8 & 2.2 & 0.7 \\
6.6 & 6.2 & 4.9 & $9.3^{\mathrm{a}}$ & 7.7 & 5 \\
\hline
\end{tabular}


Rezapour M et al.

\begin{tabular}{|c|c|c|c|c|c|c|c|c|c|c|}
\hline \multirow[t]{2}{*}{ Categories $^{\mathrm{a}}$} & \multicolumn{2}{|c|}{ Verbal } & \multicolumn{2}{|c|}{ Relational } & \multicolumn{2}{|c|}{ Physical } & \multicolumn{2}{|c|}{ Others } & \multicolumn{2}{|c|}{ Total (Bullying) } \\
\hline & $\mathbf{O R}^{\mathrm{b}}$ & CI 95\% & OR & CI 95\% & OR & CI 95\% & OR & CI 95\% & OR & CI 95\% \\
\hline \multicolumn{11}{|l|}{ Area (urban) } \\
\hline Bully only & 0.68 & $(0.34-1.35)$ & 0.67 & $(0.3-1.49)$ & 1.09 & $(0.5-2.36)$ & 0.32 & $(0.12-0.83)$ & & \\
\hline Victim only & 0.92 & $(0.62-1.36)$ & 0.9 & $(0.59-1.38)$ & 0.82 & $(0.48-1.40)$ & 0.42 & $(0.2-0.9)$ & & \\
\hline Both & 0.45 & $(0.26-0.79)$ & 0.5 & $(0.19-1.28)$ & 0.75 & $(0.31-1.79)$ & 1.79 & & & \\
\hline \multicolumn{11}{|l|}{ Gender (male) } \\
\hline Bully only & 1.93 & $(0.98-1.35)$ & 2.31 & $(0.99-5.38)$ & 3.88 & $(1.65-9.12)$ & 51 & & & \\
\hline Victim only & 3.12 & $(2.12-4.59)$ & 1.14 & $(0.76-1.72)$ & 2.60 & $(1.49-4.55)$ & & & & \\
\hline Both & 3.51 & $(1.89-6.50)$ & 1.61 & $(0.62-4.22)$ & 2.98 & $(1.15-7.72)$ & & & & $5.27)$ \\
\hline \multicolumn{11}{|l|}{ Grade (8th) } \\
\hline Bully only & 0.98 & $(0.5-1.91)$ & 0.85 & $(0.39-1.87)$ & 1.22 & & & & 1.31 & $(0.71-2.43)$ \\
\hline Victim only & 1.21 & $(0.83-1.74)$ & 1 & $(0.66-1.50)$ & 0.74 & & & 1.83) & 1.09 & (0.78-1.53) \\
\hline Both & 1.05 & $(0.6-1.85)$ & 1.55 & $(0.59-4)$ & 1.42 & $3.40)$ & & $1-8.4)$ & 1.06 & (0.68-1.68) \\
\hline \multicolumn{11}{|c|}{$\begin{array}{l}\text { a Reference groups for area, gender and grade are rural, girl and grade } 9 . \\
\text { b Alpha of } 0.05 \text { was used as the significance level. }\end{array}$} \\
\hline
\end{tabular}

The current study showed that $38.5 \%$ of the stud Mazandaran provincein North of Iran, were involved in bullying (bully only: 5.4 , victim only: 22.1 and victim-bully: 11). The results were inconsistent with those of many studies carried out in this field in various cotntries (1, $5,11,15,27-29)$. This prevalence rate was lower in compari son with those of some studies, especially for bully only that may contain a variety of reasons such as: good man agement of schools, higher peer supports, and religious beliefs that condemn bulying. In addition, there are limitations in the Iranian schools in terms of creating the conditions for the occurrence of different types of bullying behavior (cellphone ban, gender segregation, etc.). Unlike the studies conducted in the US (5), Norway (11), Italy (30) and Ireland (14), in this study, the difference between the prevalence of bullies and victims were large. Ethnic minorities are quite rare in Iranian schools and there is mainly no race minority in this country. Findings of the current study showed that bullying (bullies, victims and their forms) was more common among boys than girls, which was reinforced by some other studies (1, $3,11,30$ ). Playgrounds or sport fields, and classrooms (in he absence of teachers) and also on the way to and from chool were the most common locations of bullying. Similar results were found by studies conducted in Ireland (14) and elsewhere $(15,31)$. However, in some of the studies classrooms were the most common place where the students were bullied $(9,32)$.

In the current study, the majority of victims were bullied by their classmates. Perpetrators of bullying on victims were mainly 1 to 3 students, which was consistent with the results of a study conducted in Ireland (14). According to the scrutiny prevalence rates and correlates for the four different forms of bullying behaviors: physical, verbal, relational, and others, the findings of this study offer the distinct natures of these four forms.

In epidemiology and natural history of non-communicable diseases, latent and hidden stage before the appearance of overt clinical disease occurs (33), and since the bullying behaviors is a spectrum (1). Therefore, this mode can be considered for natural history of bullying behaviors: relational form as invisible or latent bullying and verbal form as interstitial and physical forms of bullying as overt bullying. Indeed, verbal and relational forms are early stages of bullying behaviors, therefore it can be claimed that latent forms have better prognosis compared with overt forms. According to the low prevalence of overt forms of bullying in the present study, it can be considered a better prognosis compared with similar studies conducted in America and Turkey (5, 9).

It was the first study examined bullying behaviors among the students in Iran with an epidemiological approach. Selection bias was controlled using a random sampling among all the eligible subjects in the population. However, there were some limitations in this study. First, it was a self-report study and some response biases may have occurred. Testing information from multiple sources is recommended for future studies. Another limitation was the lack of assessment for cyber bullying that is suggested for future studies. Since this study was conducted only in one province, the results cannot be confidently generalized to the whole country. Therefore, 
it is recommended to conduct further studies in various provinces. Finally, only the public secondary schools were assessed in this study and private schools were excluded. In conclusion, the pattern of bullying in Iranian schools was similar to those of many western countries, but the prevalence rate of bullies in Iran seems lower than that of the western countries. Bullying in schools is generally carried out by a minority of children, and forms of bullying are of a distinct nature in a spectrum. Results of the current study showed that bullying exists in the Iranian schools and the establishment of a surveillance system and employment of effective and appropriate interventions on this public health problem is recommended. Relevant organizations such as Ministry of Education and Ministry of Health should consider bullying among children as a serious problem.

\section{Authors' Contributions}

Study concept and design: Hamid Soori; acquisition of data: Meysam Rezapour; analysis and interpretation of data: Soheyla Khodakarim and Hamid Soori; drafting of the manuscript: Hamid Soori and Rezapour; critical revision of the manuscript for important intellectual content: Hamid Soori; statistical analysis: Khodakarim; administrative, technical, and material support: Rezapour and Soori; study supervision: Hamid Soori.

\section{Funding/Support}

This study was financially supported by Safety Promotion and Injury Prevention Research Center at Shahid Beheshti University of Medical Sciences, T

\section{References}

1. Kim YS, Koh YJ, Leventhal in Korean middle school 2004;158(8):737-41.

2. Olweus D. . Bullying at school.United States: Wiley-Blackwell,1993. ing Pula Ruan W], SimongB, Scheidt P. Bullying behaviors among US youth: prevalence and association with psychosocial adjustment. JAMA. 2001;285(16):2094-100.

4. Yen CF, Yang P, Wang PW, Lin HC, Liu TL, Wu YY, et al. Association between school bullying levels/types and mental health problems among Taiwanese adolescents. Compr Psychiatry. 2014;55(3):405-13?

5. Wang J, Iannoti RJ, Nansel TR School bullying among adoles-

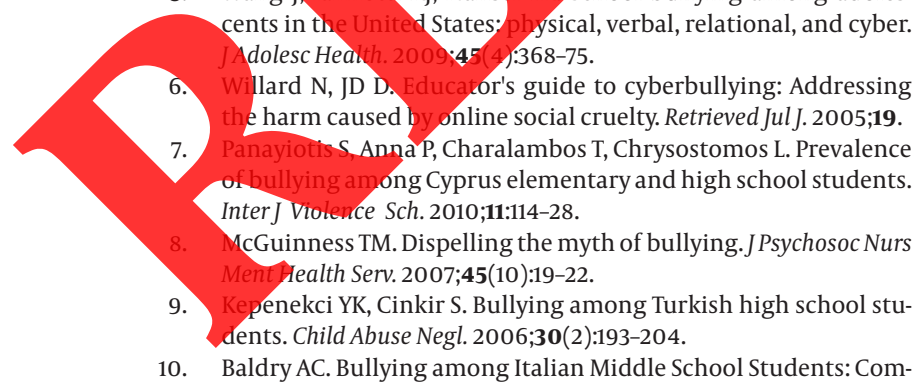

bining Methods to Understand Aggressive Behaviours and Victimization. Sch Psy Inter.1998;19(4):361-74.

11. Solberg ME, Olweus D. Prevalence estimation of school bullying with the Olweus Bully/Victim Questionnaire. Aggressiv Behav J. 2003;29(3):239-68.

12. Hong JS, Espelage DL. A review of research on bullying and peer victimization in school: An ecological systems analysis. Aggr Violent Behav. 2012

13. Craig W, Harel-Fisch Y, Fogel-Grinvald H, Dostaler Simons-Morton B, et al. A cross-national profile o victimization among adolescents in 40 cour Health. 2009;54 Suppl 2:216-24.

14. Livesey G, McAleavy G, Donegan T, Duffy J, O'Hagan C, Adamson G. The nature and extent of bullying in schools in the North of Ireland. 2007.

15. Greeff P. The nature and prevalence mediate school phase. Uni Fre

16. Hansen TB, Steenberg LM, Fair cal factors related to bellying Viol Behav J. 2012;17(4

17. NanselTR, Craig W, overpeck MD, Saluj al consistency in the relationship betwe Ruan WJ.Cross-nationbullying behaviors of bullying during t T. 2004 . and psychoso cial adjustment. Arch Pediatr J.20 04;158(8):730-6.

18. Radliff KM, Wheaton JE, Robinson K, Morris J. Illuminating the relationship between bullying and substance use among middle and high school youth. Addict Behav. 2012;37(4):569-72.

19. Gini G, Pozzoli T. Association between bullying and psychosomatic problems: a meta-analys, s. Pediatrics. 2009;123(3):1059-65.

20. Dake JA, Price JH, Telljohann SK. The nature and extent of bullygat school. J Sch Health. 2003;73(5):173-80.

21. Rezapour M, Soori H, Khodakarim S. Psychometric Properties of perpetration of Bullying and victimization scales of Olweus Bullying Questionnaire middle schools'students. Safet Promot Res Centex

Lee T, Cornell D. Concurrent Validity of the Olweus Bully/Victim Questionnaire. J Sch Viol.2009;9(1):56-73. kides L, Kaloyirou C, Lindsay G. An analysis of the Revised eus Bully/Victim Questionnaire using the Rasch measuremodel. BrJEduc Psychol. 2006;76(Pt 4):781-801.

Crothers LM, Levinson M. Assessment of Bullying: A Review of Methods and Instruments. J Counsel Dev . 2004;82(4):496-503. Hamburger ME, Basile KC, Vivolo AM. Measuring bullying victimization, perpetration, and bystander experiences: A compendium of assessment tools.: Centers for Disease Control and Prevention, National Center for Injury Prevention and Control, Division of Violence Prevention; 2011.

26. Jimerson SR, Swearer SM, Espelage DL. the Assessment of Bullying. Handbook of bullying in schools: An international perspective:. Routledg . 2010.

27. Glew GM, Fan MY, Katon W, Rivara FP, Kernic MA. Bullying, psychosocial adjustment, and academic performance in elementary school. Arch Pediatr Adolesc Med. 2005;159(11):1026-31.

28. Khezri H, Ghavam SE, Mofidi F, Delavar A. Bullying and Victimization: Prevalence and Gender Differences in a Sample of Iranian Middle School Students.J Educat Manag Study. 2013;3(3).

29. Siziya S, Rudatsikira E, Muula AS. Victimization from bullying among school-attending adolescents in grades 7 to 10 in Zambia. J Inj Violence Res. 2012;4(1):30-5.

30. Baldry AC. Bullying in schools and exposure to domestic violence. Child Abuse Negl. 2003;27(7):713-32.

31. Chabalala OR. The nature and extent of bullying at Hwiti and Mountainview secondary schools, Limpopo Province.. : University of Limpopo (Turfloop Campus); 2011.

32. Vambheim V. Bullying in school: a study of forms and motives of aggression in two secondary schools in the city of Palu, Indonesia.J sch viol. 2010.

33. Porta M. a dictionary of epidemiology. 5 edNew York: Oxford University; 2008. 